\title{
O ELEMENTAR PARA IRENE DE ALBUQUERQUE
}

\author{
Edilene Simões Costa dos Santos' \\ Denise Medina de Almeida França²
}

\section{RESUMO}

Mudanças que ocorrem no sistema educativo e na cultura escolar chegam à escola a partir da década de 1920, por meio de propostas reformistas e de legislação prescritas em vários cantos do país, dado que não existia um ministério da educação. O texto analisa o que são "saberes matemáticos nos anos iniciais", entendidos como os primeiros passos, a base inicial de conhecimentos em matemática, organizada para ser ensinada aos alunos dos primeiros anos escolares, como proposto por Irene de Albuquerque, no manual intitulado Metodologia da Matemática (1951). Buscamos fundamentos que nos permitam responder à seguinte questão: Em seu discurso sobre ensino elementar, nesse Manual de Irene Albuquerque, os saberes matemáticos são tratados como elementares ou como rudimentares? A investigação utiliza como fontes de pesquisa o referido manual, em decorrência de sua abrangência e utilização principalmente nos cursos de formação de professores da época e no ISERJ (Instituto Superior de Educação do Rio de Janeiro). Como referência teórico-metodológica, o trabalho configura-se de natureza histórica, construindo o objeto de pesquisa, a partir de elementos vindos da história cultural. Os resultados encontrados apontam que os saberes matemáticos propostos por Albuquerque são considerados como rudimentos, ou seja, são conhecimentos atrelados à vida prática, indicando as mudanças dos saberes elementares matemáticos, em consonância com a vaga pedagógica da Escola Nova.

Palavras-chave: Educação Matemática. História da Educação Matemática. Escola Nova. Ensino Primário. Matrizes teóricas. Irene de Albuquerque.

\section{ELEMENTARY FOR IRENE DE ALBUQUERQUE}

\section{ABSTRACT}

The changes that occurred in the educational system and in the school culture began to affect school practices in the 1920s through reform proposals and legislation prescribed in various parts of Brazil, since the Ministry of Education had not been created yet. This paper analyzes what are "mathematical pieces of knowledge

\footnotetext{
1 Doutorado em Educação pela Universidade de Brasília. Professora titular da Universidade Federal de Mato Grosso do Sul - UFMS. E-mail: edilenesc@gmail.com

2 Doutorado em Educação pela Universidade de São Paulo. Professora adjunta da Universidade do Estado do Rio de Janeiro - UERJ. E-mail: denisemedinafranca@gmail.com
} 
in the early years", understood as the first steps, the initial basis of mathematical knowledge organized to be taught to students attending elementary school, proposed by Irene de Albuquerque in a manual titled Methodology of Mathematics (1951). We sought grounds that would allow us to answer the following question: In the discourse about the initial education, present in this manual by Irene Albuquerque, are mathematical knowledge treated as essential or as rudimentary? The research uses this manual as a source because of its scope and uses, especially in teacher education courses in that time and in ISERJ (Instituto Superior de Educação do Rio de Janeiro). As a theoretical-methodological reference, the work is historical, constructing the object of research from elements coming from cultural history. The results show that the mathematical knowledge proposed by Albuquerque is rudimentary, that is, it is knowledge connected with practical life, indicating changes of essential mathematical knowledge, in consonance with the pedagogical propose of Nova Escola.

Keywords: Mathematics Education. History of Mathematics Education. Escola Nova. Elementary school. Theoretical matrices. Irene de Albuquerque.

\section{EL ELEMENTARIO PARA IRENE DE ALBUQUERQUE}

\section{RESUMEN}

Los cambios que ocurren en el sistema educativo y en la cultura escolar llegan a la escuela a partir de la década de 1920 por medio de propuestas reformistas y de legislación prescritas en varios rincones del país, dado que no existía un ministerio de educación. El texto analiza lo que son "saberes matemáticos en los años iniciales", entendidos como los primeros pasos, la base inicial de conocimientos en matemática organizada para ser enseñada a los alumnos de los primeros años escolares, como lo propuesto por Irene de Albuquerque en el manual titulado Metodología de las Matemáticas (1951). Buscamos fundamentos que nos permitan responder a la siguiente pregunta: $\dot{\text { En }}$ su discurso sobre enseñanza elemental, en ese manual de Irene Albuquerque, los saberes matemáticos son tratados como elementales o como rudimentarios? La investigación utiliza como fuentes de investigación el referido manual en virtud de su alcance y la utilización principalmente en los cursos de formación de profesores de la época y en el ISERJ (Instituto Superior de Educação do Río de Janeiro). Como referencial teóricometodológico, el trabajo se configura de naturaleza histórica, construyendo el objeto de investigación a partir de elementos de la historia cultural. Los resultados encontrados apuntan que los saberes matemáticos propuestos por Albuquerque son considerados como rudimentos, o sea, son conocimientos vinculados a la vida práctica, indicando los cambios de los saberes elementales matemáticos, en consonancia con bagaje pedagógico de la Escuela Nueva.

Palabras clave: Educación Matemática. Historia de la Educación Matemática. Escuela Nueva. Enseñanza Primaria. Matrices teóricas. Irene de Albuquerque. 


\section{INTRODUÇÃO}

Na história da educação matemática, são escassos os estudos que tratam sobre as filiações teóricas, dos saberes elementares matemáticos ${ }^{3}$, na escola nas séries iniciais.

Este texto, centrado nos saberes elementares, postos a serem ensinados em tempos da Escola Nova, dialoga com estudos já realizados pelo Ghemat (Grupo de Pesquisa de História da Educação Matemática), sobre as diferentes concepções de elementar no âmbito dos saberes elementares.

O período histórico da pesquisa foi determinado pelas fontes selecionadas, após um levantamento das publicações utilizadas no curso de formação de professores do ISERJ (Instituto Superior de Educação do Rio de Janeiro) $)^{4}$.

O texto procura desdobrar os saberes matemáticos, considerados por Irene de Albuquerque ${ }^{5}$, como exposto no Manual intitulado Metodologia da Matemática, que foi direcionado "para uso de professores primários, orientadores de ensino e alunos das escolas normais" como destacado na capa de sua edição de 1951.

Buscarmos fundamentos que nos permitam responder à seguinte questão: Em seu discurso sobre ensino elementar, nesse Manual de Irene Albuquerque, os saberes matemáticos são tratados como elementares ou como rudimentares?

\footnotetext{
3 Consideramos como saberes elementares: a Aritmética, a Geometria ensinada nas séries iniciais da escola, ou seja, os conteúdos a ensinar e os métodos como eram ensinados em tempos do Movimento da Matemática Moderna (MMM).

4 Para maiores esclarecimentos, ver acervos do CFPEN - Curso de formação de professores para o ensino normal. Disponível em: <http://cemiiserj.blogspot.com>. Acesso em: 19 set. 2018.

5 Nascida em 30 de outubro de 1915, cursou a Escola Secundária da Escola Normal do Distrito Federal de 1930 a 1933, ingressando em seguida no Curso Regular de Formação de Professorado Primário (ou Escola de Educação) desse Instituto. Exerceu a docência em Prática de Ensino do Curso Normal do Instituto de Educação do Rio de Janeiro, e de Metodologia dos Cursos de Aperfeiçoamento do INEP, sendo autora de livros didáticos e artigos em revistas pedagógicas. (texto elaborado pelas autoras a partir de pesquisa no Repositório UFSC).
} 


\section{CONSIDERAÇÕES TEÓRICO-METODOLÓGICAS}

$\mathrm{Na}$ articulação das questões, fizemos uso da abordagem da história cultural e nos apoiamos nos conceitos de apropriação posta por Chartier (1991). Nesse sentido, é imprescindível compreender o mundo do texto, visto que na leitura ou na escrita se dá a construção do sentido, num processo determinado historicamente, diversificando os modos e modelos de ocorrência de acordo com os tempos, os lugares, as comunidades (CHARTIER, 1991, p. 178). No nosso caso, compreender como se deu a construção teórica das propostas nas publicações, de modo a dar sentido para o tempo em que foram publicadas ou ainda como são tratados os saberes matemáticos para os primeiros anos por Irene de Albuquerque.

Para fundamentar os encaminhamentos da nossa questão, apresentamos algumas considerações sobre a representação de expert e de expertise, visto que Irene de Albuquerque é considerada como expert (VILLELA et al., 2016) Desta forma, tomamos a história da educação matemática como campo de estudo da profissionalização do professor de matemática no Brasil e, como referencial, os estudos da história da educação e da história cultural, além de concepções acerca da constituição de saberes envolvidos na formação de professores dos anos iniciais.

Refletimos ancorados na análise da docência, a partir dos saberes da especificidade dessa profissão que tratamos por saberes a ensinar e para ensinar. Segundo Valente (2015a), tais saberes são considerados sob novas bases conceituais, tendo em conta "saberes objetivados", isto é, saberes que se institucionalizam ao longo do tempo, em termos de saberes explícitos, formalizados, transmitidos e incluídos intencionalmente na formação de professores; considera o autor, ainda, que os saberes a ensinar são saberes que emanam do campo disciplinar e os saberes para ensinar compõem um corpus de saberes específicos do campo profissional. Apesar de os dois saberes, hoje, comporem o currículo de formação para o exercício da profissão de professor, é o segundo que dita a expertise profissional, ou seja, que caracteriza a profissão de professor. Mas, o que seria essa matemática 
para ensinar, a qual estamos tomando como referência? Segundo Borer (2009), os saberes para ensinar configuram-se como saberes profissionais e se desenvolvem por meio da constituição progressiva de um campo disciplinar das ciências da educação; já os saberes a ensinar são aqueles advindos dos campos disciplinares de referência, constituídos pelas disciplinas universitárias.

Hofstetter, Schneuwly e Freymond (2017, p. 131-132) definem dois tipos de saberes pertinentes à profissão docente: "os saberes que são os objetos do seu trabalho; e os saberes para ensinar, que em outros termos são as ferramentas do seu trabalho". Nesse sentido, podemos dizer que os saberes para ensinar tratam principalmente de como utilizar os objetos do ofício docente: da maneira de mobilizar o objeto do trabalho docente, sobre as práticas de ensino e sobre a instituição que define seu campo de atuação.

Esses saberes para ensinar ferramentas do ofício de professor, no campo pedagógico, vêm contribuindo para a institucionalização e desenvolvimento da expertise, que, por sua vez, participa da produção de novos saberes. Hofstetter, Schneuwly e Freymond (2017, p. 57) apresentam uma noção de expertise, caracterizando-a como uma instância atribuída a um ou mais especialistas que possivelmente se destacam em sua área de trabalho "pelos seus conhecimentos, atitudes, experiências, a fim de examinar uma situação, avaliar um fenômeno, de constatar fatos".

Valente (2017c) acrescenta que os saberes a ensinar e para ensinar na formação de professores, diferem, relativamente, aos saberes de sua formação, pelas referências colocadas historicamente. Especificamente, "para o curso primário garante-se no núcleo formativo para a profissão a presença dos saberes para ensinar" (p. 213).

Em síntese, acreditamos que o estudo histórico sobre os saberes profissionais pode elucidar as discussões que tratam da formação de professores, revelando de que maneira alguns saberes docentes foram institucionalizados e verificando a relação dessa institucionalização, com a expertise de profissionais atuantes no campo. 
Outro conceito que nos auxilia na compreensão das questões é o de apropriação, que pode ser interpretado como a prática de transformar produtos culturais, conforme Chartier (1991, p. 180):

\begin{abstract}
Apropriação, a nosso ver, visa a uma história social dos usos e das interpretações, referida a suas determinações fundamentais e escrita nas práticas específicas que a produzem. Assim, voltar à atenção para as condições e os processos que, muito concretamente, sustentam as operações de produção do sentido (na relação de leitura, mas em tantos outros também) é reconhecer, contra a antiga história intelectual, que nem as inteligências nem as ideias são desencarnadas, e, contra os pensamentos do universal, que as categorias dadas como invariantes, sejam elas filosóficas ou fenomenológicas, devem ser construídas na descontinuidade das trajetórias históricas.
\end{abstract}

Desse modo, o cruzamento das ideias das fontes filosóficas com suas apropriações por parte da referida autora, pode auxiliar na construção dos sentidos dos textos a serem analisados.

Chartier (1991) afirma que a apropriação está relacionada à liberdade, ao mesmo tempo criadora e regulada dos leitores, bem como, às múltiplas interpretações as quais um pensamento é suscetível. A leitura é sempre uma prática encarnada em gestos, espaços e hábitos. Aqui, compreender as apropriações das matrizes teóricas e fontes filosóficas realizadas, significa relacioná-las com as propostas colocadas no Manual, tentando entender como foram concretizadas em forma de propostas para o ensino de matemática. Isso nos faz tentar explicar como as ideias de pensadores da educação foram diversamente apreendidas, manipuladas e compreendidas. Em síntese, queremos apreender os modos de pensar sobre a matemática, a ser ensinada nos primeiros anos, por Irene de Albuquerque, nessa questão tratada no texto: qual é a concepção de elementar para os primeiros anos postos por Albuquerque em seu Manual? Esses saberes são os mesmos de ontem e de hoje?

Diante do exposto é necessário melhor situar o leitor, esclarecendo alguns termos e conceitos que utilizamos para compreender os saberes matemáticos postos por Albuquerque.

Os saberes matemáticos utilizam fontes filosóficas? Nessa concepção há diferenças entre saberes elementares e saberes rudimentares? 
Para iniciar, admitimos, como Valente (2016a, p. 35), que:

Parece ponto pacífico considerar que os saberes matemáticos presentes desde os primeiros anos escolares constituem os passos iniciais para a aprendizagem da matemática. $E$, ainda, que a matemática dos primeiros passos escolares é a matemática elementar. Como elementar, por extensão, também é considerada toda a matemática presente na escola básica, àquela que reúne todos os graus de ensino anteriores ao ensino superior e universitário.

Para compreender esse saber elementar, vamos considerar que há então, duas fontes filosóficas do saber elementar: uma fonte racionalista e uma corrente empirista, notando-se que elas não resultam no mesmo modelo pedagógico. Diremos que a pedagogia da tradição racionalista coloca no centro de suas concepções os valores e ideais de Razão e Conhecimento e que a pedagogia da tradição empirista privilegia a Experiência e o Sujeito (TROUVÉ, 2008, p. 13).

Trouvé (2008, p. 14) acrescenta que, embora as duas tradições corroborem em começar a aprender com os elementos mais simples do conhecimento, elas não compartilham a mesma concepção de "simples" e de "elementar", isto é, a primeira considera que o "simples" reside na abstração, enquanto a segunda considera que o "simples" está na "concretude". A primeira argumenta que o conhecimento elementar, deve primeiro se referir às disciplinas mais abstratas (como a geometria), envolvendo essencialmente atividades intelectuais; a segunda deve referirse às disciplinas consideradas mais "concretas", como as famosas lições das coisas, mobilizando a primeira percepção sensível, por meio das ilustrações. Para os racionalistas deve-se caminhar de generalidades a particularidades (isto é, noções para coisas). Já para os empiristas, pelo caminho oposto, isto é, progredindo da experiência de coisas particulares, para a compreensão das leis gerais que governam essas mesmas coisas. Mas, em ambos os casos, deve ser "elementar", isto é, ser "simples". Assim, notamos que os passos também separam as duas correntes filosóficas, na medida do que se chama de "método dedutivo" e de "método intuitivo" (ou "sensível"). 
Em suma, acreditamos que é possível distinguir dois tipos de heranças presentes no pensamento pedagógico de hoje: um originário do racionalismo universalista, outro do naturalismo evolucionista do séc. XIX.

Dentre os pensadores iluministas, podemos considerar Condorcet (1743-1794) como um dos maiores representantes que divulgou em suas obras a ideia de uma educação fundamentada nos conteúdos de ensino. Pensando assim, o número de disciplinas precisa ser aumentado e a ênfase dos Programas de ensino ficaria por conta das Ciências naturais e humanas. Nessa concepção racionalista, a aquisição de conhecimentos é maior valorizada.

Podemos dizer que as duas escolas, o empirismo e o racionalismo sempre estiveram em embate: qual deve ser a maneira correta do conhecimento? Locke (1632-1704) pensa diferentemente de Descartes (1596-1650) em relação ao modo como o conhecimento é adquirido. Descartes, racionalista, buscava a origem das ideias no campo da razão, via dedutiva. Já Locke vai interessar-se por sua gênese, a partir de fatos empíricos, via indução (PINTO, 2017). Descartes dá ênfase à simplicidade dos primeiros conhecimentos, acreditando que o conhecimento parte do simples até o complexo, usando a razão. Locke enfatiza que a experiência, ou seja, a experiência sensível é fundamental, e o que vem depois da razão depende dessa experiência.

Locke é um pensador que revoluciona o pensamento de Aristóteles e de Descartes sobre a teoria das ideias inatas - conhecimentos com os quais, segundo esses teóricos, o homem já nascia - propondo a teoria empírica, na qual todos os conhecimentos do homem são aprendidos ao longo de sua existência.

Em 1759 os iluministas Denis Diderot e Jean D'Alembert se uniram para compilar todo o conhecimento racional conhecido até então numa única obra, a Enciclopédia das Ciências, Artes e Ofícios.

Podemos induzir que o ensino dos saberes matemáticos oriundos de heranças do pensamento iluminista baseia-se em conhecimentos 
propedêuticos, preparatórios, enfatizando a continuidade, graduação, em que a ordem do ensino é a ordem epistemológica da disciplinab.

Após a Revolução Francesa mudanças são emergentes: a educação intelectualista não é mais vista como o propósito maior. Esse tipo de cultura é considerado como individualista, só servindo àqueles que se instruem. Nesse cenário podemos dizer que nasce um novo pensamento pedagógico, que encontra em Pestalozzi o seu principal idealizador (VALENTE, 2015b). Com ele, a Pedagogia promove a sabedoria para todas as crianças do povo, uma escola em que ação e pensamento caminham juntos, tomando o lugar do pensamento abstrato.

Considerando as concepções de Pestalozzi, o pensamento pedagógico passa a preocupar-se também com a formação do caráter. Valente (2015b) ressalta que o centro da gravidade do ser, não mais seria a sua razão, que se desloca para a ação do indivíduo, sendo vista como um produto de adaptações do ser às suas condições de vida.

Podemos resumidamente dizer que o ser humano racional cede lugar a um homem sociológico, particular em que a natureza é informada por seu meio. Em síntese, nas pedagogias racionalistas, o saber elementar está mais bem caracterizado pelas disciplinas mais abstratas, com ênfase na ideia de elementos, das primeiras partes simples de um saber que avança. Já, para as empiristas, o elementar liga-se às rubricas mais concretas que mobilizam a percepção sensível. Mais especificamente, o que se propõe para ser ensinado nos primeiros anos é chamado de rudimentos, as partes úteis para a vida prática, não implicando continuidade e preparando o sujeito para os rudimentos da vida.

Também concordamos com Oliveira (2017, p. 24), quando declara:

[...] uma vaga pedagógica pode ter sua gênese nas demandas da sociedade. Uma vaga pedagógica intenta varrer as práticas consideradas obsoletas da escola e as substituir por outras. Ela, a vaga, busca transformar não só as práticas escolares, mas também

\footnotetext{
6 Para uma discussão mais aprofundada sobre a apropriação de ideias iluministas em propostas pedagógicas, pode-se ler o texto de VALENTE (2016), em que se discute o Programa proposto por Caetano de Campos.
} 
outros instrumentos/dispositivos que inventam o cotidiano escolar, a exemplo dos saberes e dos exames aplicados para se tornar professor das escolas primárias.

Assim, diante desse cenário brasileiro, em que as ideias escolanovistas estavam disseminadas, é necessário aprofundar o estudo sobre a concepção dos saberes matemáticos dos primeiros anos postos por Albuquerque - visto que seu Manual foi utilizado por diferentes estados brasileiros (VILLELA et al., 2016) e por um período muito longo, embasando muitas práticas e norteando transformações no ensino de Matemática no período proposto - a fim de compreender a repercussão de concepções filosóficas teóricas na organização de saberes elementares matemáticos e as propostas de como abordá-los.

Pedagogicamente, rudimentar e elementar possuem interpretações diferenciadas. Entender as diferenças é fundamental para compreender a maneira da matemática "para" e "a" ensinar, proposta no Manual. (VALENTE, 2017c).

Afinal, o Manual de Albuquerque está embasado em elementos ou rudimentos?

Consideramos que, em tempos da Escola Nova, conforme Valente (2016a, p. 43):

Somente os rudimentos poderão se articular com os problemas da vida cotidiana. Com eles forma-se o aluno que aproveita a parte útil e transferivel do saber para a vida comum. Não se trata de iniciar o aluno no percurso da ciência, dando-lhes os elementos de cada saber avançado. A escola dos primeiros anos é prática, tem caráter terminal e precisa usar o seu tempo formativo para melhor municiar os alunos que dela saírem com os instrumentos úteis à vida de cada um.

Nos saberes rudimentares, em suma, o trabalho parte do mais simples para o mais complexo; do concreto para o abstrato; das particularidades para as leis gerais; de elementos cotidianos e que são próximos da realidade do aluno, para, em seguida, utilizar-se de conceitos mais abstratos e conceituais. (VALENTE, 2016a).

E elementar qual é seu significado? Trazemos Trouvé (2008, p. 12) para afirmar que 
Se considerarmos a ideia de elementaridade tomada por si mesma, nós deveremos reconhecer que ela é tradicionalmente referida a uma dada concepção de saber, onde este último se estrutura em elementos.

Ora, isso nos remete à filosofia cartesiana, por ter constituído um referente paradigmático dessa concepção de saber, origem da noção de saber elementar. Assim considerando, podemos dizer que os saberes matemáticos elementares bebem da herança racionalista. A pedagogia agregada a essa corrente defende a continuidade de estudos e o encadeamento epistemológico das disciplinas, o simples reside na abstração e aprendem-se generalidades para particularidades pelo método dedutivo.

Dessa forma, o que orientava o Manual de Irene de Albuquerque? A Aritmética atendia a uma finalidade elementar (como princípios fundamentais de uma disciplina mais avançada) ou rudimentar (como elementos essenciais e indispensáveis para a vida prática)?

\section{CONSIDERAÇÕES SOBRE O MANUAL METODOLOGIA DA MATEMÁTICA}

Como fonte principal de estudo, tomamos o Manual de Metodologia da Matemática, publicado em 1951. A análise de tal manual nos permitiu uma reflexão, em torno de aspectos relacionados ao ensino dos saberes elementares nos primeiros anos, considerando que dentro desse cenário brasileiro emergiam transformações:

O contexto histórico-político-social brasileiro é de afirmação do nacionalismo, de preocupação das elites dirigentes com o problema do analfabetismo e falta de escolaridade para a maioria da população, em face aos países considerados avançados. Os discursos sobre a Educação fazem contraponto àqueles enunciados em tempos de início do período republicano. E esses discursos são pronunciados por uma nova geração de educadores que é forjada pelas escolas normais (VALENTE, 2017b, p. 374).

Iniciamos o texto por uma descrição da estrutura do material para, em seguida, buscarmos elementos que nos permitiram auxiliar na resposta da nossa questão: Que concepção de saberes matemáticos nos anos iniciais 
pode ser lida no Manual Metodologia da Matemática de Irene de Albuquerque?

O estudo da materialidade do objeto nos levou a observar primeiramente sua estrutura física: na capa observamos um cabeçalho com - nome centralizado e maiúsculo, "METODOLOGIA DA MATEMÁTICA" seguido do nome da autora e sua biografia: "Catedrático de Prática de Ensino do Inst. de Educação do D. F. Professor de Metodologia da Matemática dos Cursos de Aperfeiçoamento do INEP. Professor de Curso Primário".

Tudo leva a crer que a biografia da autora exposta na capa, seja utilizada como estratégia, a fim de auxiliar no convencimento de sua proposta. Ainda percebemos o fato de o ofício estar no masculino, mas isso não nos toma a atenção nesse estudo. Na continuidade, abaixo do nome do livro, está informado a que se destina: "Orientação detalhada e sugestões práticas acerca de todos os pontos do programa do curso primário". Separado por uma pequena estrela, que determina um espaço de diagramação, está expresso a quem se destina: "Para uso de professores primários, orientadores de ensino e alunos das Escolas Normais"; mais um espaço e temos informado: llustrações de Cosette de Albuquerque. Ao final, está a editora: "Conquista". Na contracapa está acrescido o ano de edição, 1951, e o endereço da editora: Av. 28 de Setembro, 174 - Rio de Janeiro. Mais uma vez, podemos dizer que a capa carrega estratégias de convencimento sobre a cientificidade do Manual, estratégia de convencimento aos professores, sobre a adequação da nova proposta, na medida em que a autora discute a matemática para ensinar a matemática a ensinar (VALENTE, 2017c) na escola primária.

O livro é composto de introdução e outras duas partes. No sumário a primeira parte está dividida em oito capítulos, nos quais, a autora parece manter um monólogo de explicação e convencimento ao leitor de questões que podem ajudar o professor, a cumprir sua tarefa de ensinar matemática às crianças, ou seja, orientações sobre a matemática para ensinar. Na segunda parte, a autora trata mais especificamente o "para" ensinar de 
cada conteúdo "a" ensinar. No caso, noções de geometria, noção de número, contagem numeração; fatos fundamentais; operações fundamentais com os números inteiros; cálculo mental abreviado; frações ordinárias e decimais; sistema monetário brasileiro; noções fundamentais do sistema métrico; perímetro, área e volume; noções de proporcionalidade e regra de três simples; porcentagem e juros.

FIGURA 1: Índice de Metodologia da Matemática
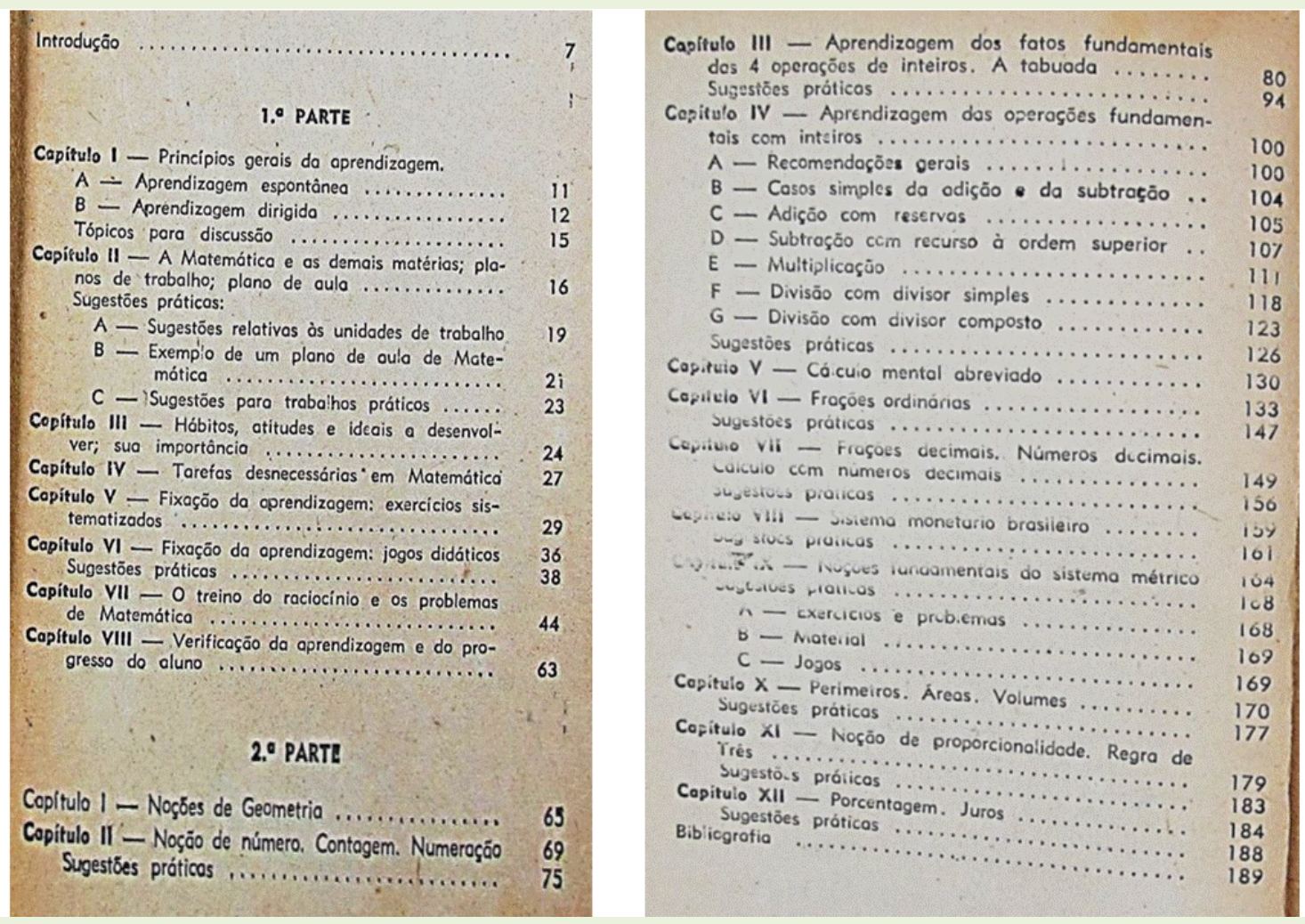

Fonte: Albuquerque (1951).

Percebemos a extensão da listagem de conteúdo. Algumas considerações podem ser feitas, quando olhamos essa listagem de conteúdos, a fim de problematizar a escola primária da época. A leitura do Manual demonstra a representação desse ensino, relacionada com 0 princípio da terminalidade. A preocupação maior, expressa pela quantidade de conteúdos previstos a serem desenvolvidos em apenas quatro anos, revela uma preocupação em suprir os alunos com rudimentos, 
visto a entrada no mercado de trabalho. Prosseguindo nesse raciocínio, supõe-se que, naquela época, não havia muitas chances de que a maioria das crianças pudesse ter continuidade de estudos; logo, a escola primária deveria tentar proporcionar o máximo de conteúdo possível no pequeno período em que a escolarização era obrigatória e gratuita, ou seja, em grande medida, em seu destino, o estudante que aprendia apenas os rudimentos tinha oportunidade de entrada garantida no mundo do trabalho.

Na introdução a autora define o público a quem se destina o manual e sua finalidade:

É apenas uma contribuição honesta aos alunos das escolas normais que se preparam para a missão de ensinar, aos auto-didatas, ou aos que têm função de orientar professores com pouca experiência, ou ainda, aos mestres sinceros que não se sentem plenamente satisfeitos com os resultados obtidos em seu ensino (ALBUQUERQUE, 1951, p. 9).

O índice e a definição de tal público nos levam a julgar que os dois tipos de saberes pertinentes à formação docente serão abordados (HOFSTETTER; SCHNEUWLY; FREYMOND, 2017), e consideramos que o material é desenvolvido para cumprir com o que se propõe.

Anterior a tal citação, ela assinala que as dificuldades apresentadas por alguns alunos com aprendizagem estão relacionadas ao método pelo qual o professor ensina. Ainda nessa situação, ela se refere que a dificuldade se relacionava a falhas na literatura e nas noções básicas de matemática. Acrescenta que certo aluno foi submetido a uma revisão do conteúdo utilizando o método proposto, por isso ele passa a acompanhar os alunos do segundo ciclo. Essa situação aponta que a autora considera que a matemática pode ser trabalhada com o aluno do fácil para o difícil, começando pelo mais simples, a partir do que ele sabe.

As preocupações com os novos estudos da Pedagogia e Psicologia são acentuadas pelo modo com que a autora reitera a adequação do conteúdo ao desenvolvimento da criança. $O$ fato pode ser explicado pelos avanços da Pedagogia, que procurava incorporar os conhecimentos da Psicologia de base biológica e fisiológica, e também da Estatística, pois, com uma 
[...] melhor caracterização da infância (e consequentemente do adulto); ao se estabelecerem as constantes do desenvolvimento, os estágios de maturação e a identificação das diferenças individuais, almejava-se renovar as técnicas de ensino (MONARCHA, 2009, p. 45).

Outro ponto que destacamos refere-se à inserção da criança em situações nas quais ela possa "redescobrir" a matemática. De acordo com a autora, se a criança for "capaz de descobrir uma regra e chegar a enunciála, esta regra está sabida para sempre" (ALBUQUERQUE, 1951, p. 7).

A referência à descoberta pela criança está relacionada ao método de ensino vigente na Escola Nova, o Método da Descoberta, fundamentado nas ideias pedagógicas do filósofo americano John Dewey (1859-1952).

No capítulo sob o título Princípios gerais da aprendizagem, o discurso parece retomar conceitos relacionados ao movimento da Escola Nova, quando a autora assevera que as crianças não têm interesse em resolver problemas dos outros, por isso, o professor deve trabalhar com questões do cotidiano da criança, com base na vida real. Cabe aqui destacar heranças do conhecimento rudimentar que enfatiza o utilitário do conhecimento para o cotidiano.

A autora afirma que, doutra sorte, seria um ensino tradicional revestido de moderno. Para comprovar suas inserções, alega que, nas escolas rurais, o cotidiano tem sido o centro das atividades escolares, o que tem despertado nas crianças interesse por questões mais intelectuais.

\begin{abstract}
Sabe-se que a criança tende a conhecer e a formar seu pensamento ao império de necessidades que a impelem à ação, segundo impulsos e interesses naturais. É pela ação, que o homem se educa e se reeduca; a obra educativa, porque não cessa, não pode ser tomada como "preparação para a vida". Ela é, agora, posta em termos da experiência, funcionalmente aproveitada ou incorporada à personalidade do educando, de tal modo que possa ser "reconstruída", segundo as novas situações que o educando defronte. É, assim, menos desenvolvimento e preparação, que ajustamento da capacidade, para progressivo reajustamento. Nessa compreensão, todas as capacidades do indivíduo interessam, as do corpo, as da mente, as do caráter - juntas, porque são inseparáveis (LOURENÇO FILHO, 1945, p. 317).
\end{abstract}

Ainda, nesse capítulo, Albuquerque apresenta pontos que devem ser considerados pelo professor para que a criança não tenha dificuldades em 
aprender matemática. Um desses pontos é a valorização do uso do material para que a criança possa ver, pegar e sentir as coisas:

Ao invés de ensinarmos a fórmula para achar a área do triângulo, permitiremos que ela, com papel e tesoura, veja que pode partir um paralelogramo em dois triângulos iguais e, daí, "redescobrirá" como achar a área do triângulo (ALBUQUERQUE, 1951, p. 13).

Nessa citação, podemos perceber o valor do material concreto para uma matemática que é descoberta pelo aluno, e não construída. Ou seja,

Tornar o conhecimento concreto: Ex: Contar coisas, ao invés de enunciar números de 1 a 100; medir extensões com um metro ou uma fita métrica, ao invés de papaguear uma lista de múltiplos e submúltiplos, usados ou não. A criança gosta de ver, pegar, sentir as cousas. Quanto mais nós apelamos para os seus sentidos, melhor é a aprendizagem. Usar objetos do mundo real, desenhos, massa plástica, papel e tesoura, etc, ajudam muito mais que longas explicações ou infindas decorações (ALBUQUERQUE, 1951, p. 13).

Esse discurso coaduna com os princípios da Escola Nova, visto que para Vidal (2000), a escola deveria oferecer situações em que o aluno, a partir da visão (observação) e da ação (experimentação), pudesse elaborar seu próprio saber. "Deslocado do 'ouvir' para o 'ver', agora o ensino associava 'ver' a 'fazer'" (VIDAL, 2000, p. 498). Além disso, a nova escola estava fundada no princípio da "interpenetração da psicopedagogia com as questões da vida social" (MONARCHA, 2009, p. 145).

Ao longo do livro, Albuquerque (1951) faz referência ao ensino gradual. Para a autora, gradual significa começar do mais simples adequando a abordagem segundo as dificuldades da criança de acordo com sua lógica psicológica. O processo educativo se dá de dentro para fora dirigido ao interesse do aluno, ou seja, à necessidade do individuo. Além disso, enfoca que o trabalho com a criança na escola deve ser iniciado inserindo-a em um ambiente que the seja familiar, natural, na vida ativa que a rodeia para que ela possa ver, sentir e descobrir as noções matemáticas conforme suas possibilidades.

Ainda no decurso do livro, a autora evidencia que, constantemente, a criança deve ser estimulada a avançar em busca de recursos necessários e que estejam em seu alcance para realizar determinadas ações, que a 
levarão à descoberta do conceito da aritmética em estudo. Essas orientações parecem apontar em direção ao rudimentar? Seria isso mesmo?

Seguindo na análise do livro, detemo-nos, na escrita do texto, somente em pontos diretamente voltados ao nosso objetivo, ou seja, na abordagem de elementar em Irene de Albuquerque; por exemplo, quando a autora fala da aprendizagem dirigida, um dos pontos a ser observado pelo professor, que é considerado um mediador, é a dosagem da dificuldade: "A escola fará êsse trabalho de seleção e dosagem, ensindo-lhe pouco de cada vez, primeiro o mais fácil, depois o mais difícil." (ALBUQUERQUE, 1951, p. 14).

Valente reconhece que a vaga pedagógica da Escola Nova reforça a ideia de que a abordagem dos conceitos pode ser realizada preocupandose com a ordem lógica dos conteúdos, partindo-se do fácil para o difícil:

A partir de trabalhos como esse, instala-se o novo par fácil/difícil. As referências para o ensino não mais devem encadear-se segundo a ordem lógica de organização do conteúdo matemático herdada de tempos anteriores. À ordem lógica deve sobrepor-se a psicológica. Ao simples/complexo, o fácil/difícil. Em síntese: à ordem do ensino, a ordem da aprendizagem (VALENTE, 2015b, p.365).

No final do Capítulo I, no qual a autora discute os princípios fundamentais da aprendizagem, é apresentada uma nota de rodapé, em que Albuquerque cita sua filiação teórica, destaca o trabalho com figuras para elaboração de problemas e, também, evidencia o método de projeto, o qual ela chama ao longo do livro de Unidade de Trabalho.

FIGURA 2: Nota de rodapé

NOTA - Exemplificamos aqui tópicos de conhecimentos guagem e matemática programas que dão as sugestões para linvura, em tôrno da qual Convém acentuar, ainda, o valor da gra-

culas de linguagem e problemas e derivar as

balhos manuais dem conhecimentos. O desenho e os tra-

dáo, por sua vez, novos mom-se com a unidade de trabalho

Adotamos, quer motivos à Matemática.

Planos de Aula, a orientac Unidades de Trabalho, quer para os

de de Janeiro pela catedrática no Instituto de Educaçāo do

Paiva souza.

Fonte: Albuquerque (1951, p. 21).

Revista Exitus, Santarém/PA, Vol. 9, N², p. 186 - 212, ABR/JUN 2019. 
No curso dos capítulos, a autora demonstra a sua postura como formadora de formadores: orientando e chamando a atenção, para situações mais comuns que acontecem no processo da educação matemática da escola primária; fazendo várias referências ao método da descoberta, ao trabalho com problemas ligados a situações de interesse da criança, situações que devem the ser familiares e cotidianas; fazendo alusão ao valor da motivação para que a criança possa aprender e estar disposta a caminhar na direção de conhecimentos matemáticos mais difíceis.

A autora inicia o Capítulo III anunciando que "a aprendizagem dos fatos fundamentais da adição e subtração, assim como dos da multiplicação e divisão é a etapa mais importante da aritmética, na escola primária" (ALBUQUERQUE, 1951, p. 80) e informando que a falta de segurança nas combinações é motivo de dificuldades com a aritmética nas séries mais adiantadas. Então, propõe pontos por ela considerados essenciais ao ensino das várias combinações dos números e dígitos.

No Capítulo V, denominado Fixação da aprendizagem: exercícios sistematizados, a autora defende a importância de exercícios para fixação de uma noção que o aluno entendeu e orienta a elaboração dos mesmos. Uma dessas orientações define que os exercícios sejam seriados, dispostos em ordem crescente de dificuldade. Ao longo dos capítulos percebemos a insistência na necessidade de graduar a dificuldade, considerando a idade mental da criança, de modo a ter condições de assimilar os conceitos da matemática que devem estar relacionados às necessidades da vida prática e ajustados aos rudimentos do ensino.

Como podemos perceber, as orientações de Albuquerque estão de acordo com que a criança aprenda a matemática que lhe é próxima, para ajudá-la na resolução de problemas que Ihes são pertinentes e reais. A criança deve aprender matemática pela descoberta a partir de situações de seu cotidiano e com uso de materiais, e nunca pela memorização.

No Capítulo VII, denominado O treino do raciocínio e os problemas de Matemática, Albuquerque evidencia que não se deve primar pela memorização, mas pelo treino do raciocínio. Nesse capítulo, também, é 
possível considerar a matemática para ensinar. No início do capítulo a autora explica que não só os problemas ajudam a treinar o raciocínio, mas que qualquer ensino deve favorecer a criança a pensar e a refletir: "ao dar uma noção nova de cálculo, devemos levar a criança a 'redescobri-la'; essa redescoberta faz-se à custa de raciocínio" (ALBUQUERQUE, 1951, p. 44). No decorrer do capítulo, a autora trata de saberes profissionais, ou seja, saberes referentes a sua prática:

[...] o primeiro cuidado do professor consiste no planejamento do problema. [...] é preciso pensar a) Êsse problema sinteressará aos meus alunos? Tem relação com a sua vida infantile É relativo à vida adulta mas tem, relamente, probabilidade de ocorrer? [...] b) - É adequado à minha classe e corresponde às necessidades dos meus alunos: quanto às noções de matemática cujo treino envolve? Quanto à fificuldade de raciocínio? [...] p problema serve, ainda ao treino de raciocínio enão do cálculo, logo os cálculos longos devem ser abonados, pois desviariam a atenção da crinaç do raciocínio para o cálculo. [...] c) A linguagem em que está redigido o problema é clara, correta, adequada, simples? d)Em relação aos problemas anteriores dados em classe, há uma variedade de tipos? (ALBUQUERQUE, 1951, p. 44-45).

Em continuidade às orientações para ensinar problemas, Albuquerque explicita os tipos de problemas, como problemas da vida real, problema-historieta, problemas sem números, problema incompleto, problemas em série, problema sugerido por gravura, problema para vestir, problema para encontrar o dado desnecessário e problemas orais. Depois de explicá-los e como trabalhar com cada um deles, ela discute a Motivação do problema. Como nos demais conteúdos abordados, o professor deve pensar em um motivo que dê razão ao problema, de maneira que a criança o deseje por se tratar de uma necessidade imediata. Assim, o professor não deve deixar que a única motivação em sala de aula "seja condicionada pelo aparecimento de situações ocasionais". (ALBUQUERQUE, 1951, p. 49).

Em seguida, a autora explica como e quando o professor deve proceder a redação do problema no quadro-negro, estabelecendo que é tarefa do professor, ensinar que tipo de leitura é usada no problema e como essa leitura deve ser feita. Posto isto, afirma: 
Todos os professores conhecem casos de alunos que raciocinam bem, que são ótimos leitores de textos recrativos, mas incapazes de resolver um problema que não Ihes seja apresentado oralmente. Trata-se simplesmente de falha no mecanismo de leitura especial para problemas (ALBUQUERQUE, 1951, p. 50).

A autora parece trabalhar no convencimento do professor, de que há uma estratégia específica para a leitura de problemas matemáticos, e que o professor deve fazer o uso de um determindo protocolo de leitura oral, para que o aluno possa usá-lo na leitura silenciosa, e assim perceber o significado que o problema apresenta. Por conseguinte, passa a apresentar os métodos de resolução de problemas, tecendo críticas ao uso de "problemas-tipos", por apresentarem situações estandardizadas, que levam à mecanização de soluções. A autora entende que, por não haver número suficiente desses tipos para apresentar à criança todas as situações da vida, o que poderia levá-la ao erro, tanto na escola, como fora dela, deve ser estabelecido um método geral que, indiretamente, atenda a todos os problemas. Trata-se, então, de iniciar a resolução do problema por uma leitura oral:

Através dessa análise oral, sempre rigidamente orientada pelo professor, para que o aluno forme o seu método de ataque a qualquer problema, é que a criança aprende, realmente, a solucioná-lo (ALBUQUERQUE, 1951, p. 51).

A análise oral, segundo a autora, é realizada por meio de questionamentos ao enunciado do problema. Para ilustrar, cita algumas perguntas, apresentando um exemplo detalhado na questão da análise. Para o tópico resolução de problema determina mais um protocolo, justificando que tal hábito auxilia na legibilidade da solução e na organização dos registros dos cálculos e operações realizadas. Ressalta a necessidade de clareza nas respostas que devem estar em acordo com os termos da pergunta. Em seguida, discute rapidamente alguns pontos: resolução individual do problema; correção do problema; vocabulário usado nos problemas; erros em solução de problemas cometidos pelas crianças do Distrito Federal nas provas finais.

Podemos inferir que a autora sistematiza saberes para ensinar, à medida que orienta como o professor pode fazer para abordar conteúdos. 
Além disso, em uma seção denominada Medida do raciocínio em Aritmética, Albuquerque trata a questão da medida da habilidade das crianças para resolver problemas. Cita alguns testes, orientando a organização das provas e termina o capítulo com sugestões práticas. O fato pode indicar a intenção da autora de se aproximar da Pedagogia Científica ${ }^{7}$.

Detemos-nos em tratar com mais atenção esse capítulo por entendermos que ele nos ajuda a apresentar a matemática para ensinar presente em todo o livro. O exemplar é muito rico, visto que dialoga com o professor relacionando a matemática a ensinar e para ensinar, aconselhando o que "fazer", o que "evitar", como proceder em algumas situações e, também, fazendo antecipações. Talvez pelo fato de a autora conhecer dificuldades do professor, faz prescrições tentando dar segurança na aplicação de suas propostas.

Quanto às operações, bem como todos os conteúdos abordados no Manual, a autora orienta para a objetivação, ou seja, a significação para a criança a partir do cunho utilitário do saber em questão, o que nos remete mais uma vez à percepção rudimentar do saber elementar.

Oliveira (2017, p. 235) afirma:

Em termos de cálculos, adição e subtração eram trabalhadas simultaneamente. Assim como a multiplicação e a divisão. A ideia era sempre trabalhar com o cálculo nas diferentes combinações e, com isso, formando a ideia de que um número resulta da composição e decomposição de outros números.

Esse fato anunciado é encontrado no livro de Albuquerque, conforme a figura a seguir:

\footnotetext{
7 Pedagogia Científica: trata-se de um tempo em que a presença dos processos matemáticos e estatísticos foi fundamental para a caracterização das Ciências da Educação, tendo os testes como a sua face mais visível. (VALENTE, 2016b)
}

Revista Exitus, Santarém/PA, Vol. 9, N² 2, p. 186 - 212, ABR/JUN 2019. 
FIGURA 3: Composição e decomposição de números

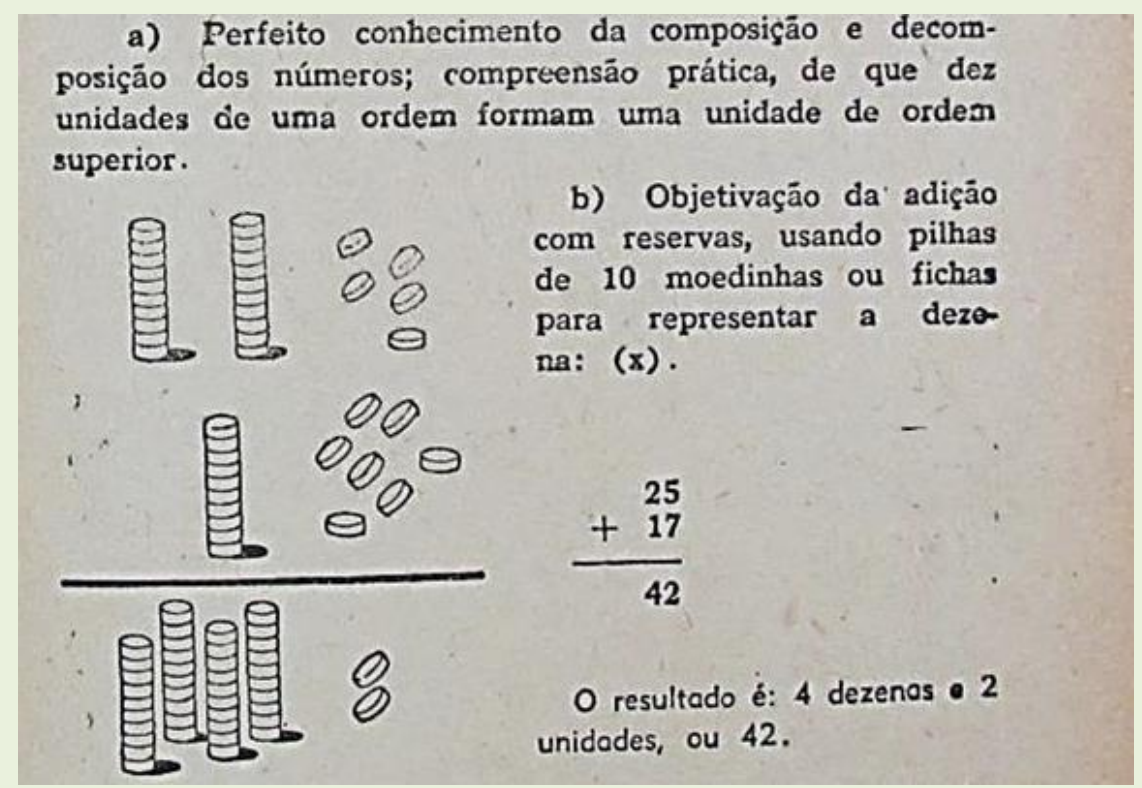

Fonte: Albuquerque (1951, p. 105).

A autora defende que o ensino deve seguir uma ordem psicológica, respeitando a idade da criança, sendo graduado de noções mais fáceis para as mais difíceis, como podemos perceber nesse trecho:

O treino de cálculo mental abreviado deve ser progressivamente intensificado, por exercícios sistematizados de cálculo mental, nos quais os alunos empreguem processos abreviados de cálculo que Ihes foram ensinados (ALBUQUERQUE, 1951, p. 130).

A autora apresenta outras questões que nos levam a inferir que em sua obra há um direcionamento aos saberes rudimentares, pois com a ideia de que a criança não deve ser ensinada para a vida, e sim na própria vida, o saber ganha o sentido utilitário e, então, a matemática a ser ensinada tem a força em seus rudimentos, como podemos perceber nesses textos: "Calcular o m.d.c. é uma tarefa muito longa e sem valor para simplificação de frações. Não tem qualquer utilidade na vida comum" (ALBUQUERQUE, 1951, p. 137). "Objetivação é da máxima importância para a formação do número. 'Objetivar é relacionar o número com a realidade, o que the dá significação'" (ALBUQUERQUE, 1951, p. 69). Os problemas com dinheiro são dos mais comuns no uso cotidiano e, portanto, neles deve ser a criança treinada, exercitando a leitura, a escrita, os cálculos de quantidades. "A 
criança deve saber objetivamente e de cor quantos quartos há num meio, quantos oitavos há num quarto, etc." (ALBUQUERQUE, 1951, p. 135).

Todo o conteúdo é orientado para ser trabalhado objetivamente, adquirindo significado em sua estreita relação com a realidade da criança. Assim, a autora aponta se é interessante ou não trabalhar com algum conteúdo em particular - como, por exemplo, na questão do m.d.c. mencionado acima, pois afirma que no currículo ele "aparece" por arcaísmo do próprio currículo (ALBUQUERQUE, 1951, p. 137) - e, em outros momentos, ressalta a necessidade de serem trabalhados porque estão presentes no cotidiano das crianças, como, por exemplo:

A divisão de fração por um número inteiro também aparece na vida: É o caso em que, por exemplo, uma receita de bolo vai ser feita apenas pela metade. É preciso, pois, dividi-la ao meio, isto é, dividi-la por 2 (ALBUQUERQUE, 1951, p. 145).

Como anunciado no início deste texto, o livro em estudo foi editado em 1951, tempos do Movimento da Escola Nova no Brasil. Quando olhamos para esse contexto, podemos considerar que há ênfase para experiências coadunando com o desenvovimento psicológico das crianças, ou seja, considera-se a ordem natural da aprendizagem pela criança, caminhando, progressivamente, do fácil para o difícil. Assim, os conteúdos são apresentados conforme a lógica da aprendizagem, não a lógica interna da matemática e, dessa maneira, o Manual corrobora os modos de ensino apregoados pelos escolanovistas.

\section{ALGUMAS CONSIDERAÇÕES}

Algumas problematizações podem ser colocadas após nossa análise. Podemos inferir que nesse livro, que tem o normalista como principal público, a autora orienta para um ensino organizado sob medida para a criança, que deve ser respeitada na idade e como alguém que pode aprender ativamente, com processos que podem ser individualizados para atender alguns alunos com determinadas dificuldades.

Um ponto a destacar refere-se à reiteração da editora em caracterizar a autora como especialista de prestígio na área; inclusive na orelha do livro, 
a autora é retratada como aquela que traduzirá aos futuros professores ou aos inseguros as diretrizes para o ensino de matemática:

Trata-se de livro destinado àqueles que não estão muito seguros em questões de linguagem, desejam melhorar seus conhecimentos básicos. Estão escritos com a maior clareza possível, sem preciosismos nem rebuscamento de linguagem que tornam detestáveis certos livros. Não basta num livro didático que o autor tenha conhecimento da matéria, cumpre que as explicações sejam compreensíveis. Para tanto, é necessário que o sentido da frase seja claro (ALBUQUERQUE, 1951, Orelha).

Podemos dizer que a proposta de Albuquerque corrobora as ideias escolanovistas, visto suas prescrições para $\mathrm{O}$ ensino de matemática: concordava que o aluno deveria ser o elemento ativo da aprendizagem e para isso o professor deveria proporcionar atividades que exigissem participação e também momentos de individualização.

Há inúmeras orientações na coleção sobre a emergente necessidade de o futuro professor considerar a Psicologia e Pedagogia como saberes inerentes a seu ofício. Uma característica marcante é a ênfase dada às contribuições da Psicologia e da Pedagogia nas suas propostas, considerando-as, por isso, em constante evolução, a fim de adaptar-se ao desenvolvimento das pesquisas mais recentes, tanto na Matemática como na Psicologia e, portanto, sujeitas a mudanças significativas. Percebemos ao longo do texto do Manual o uso de explicações retiradas de conceitos da Psicologia e críticas ao que chama de "ensino que apela muito à memória", fazendo parte de seu estilo, ao construir a argumentação, apontar equívocos e criticar a ineficiência e a inadequação da metodologia antiga antes de anunciar proposições metodológicas para 0 ensino de Matemática. Para Albuquerque (1951, p. 7),

A Matemática não é difícil, mas ensinar Matemática é tarefa que exige maior dose de reflexão, de bom senso e de cuidado [...] por ser uma ciência. [...] o professor erra algumas vezes, antes de encontrar o caminho certo para ministrar dada noção; e, enquanto o professor está errando, o aluno não está aprendendo.

Voltando a nossa questão: De que maneira podem ser lidos os saberes matemáticos postos no Manual de Irene de Albuquerque: rudimentos ou elementos? 
Após a análise do Manual, podemos considerar que nele a autora trata da iniciação na criança em matemática - a partir do que essa traz como bagagem cognitiva e afetiva -, de uma maneira sistemática e que essa sistematização não deve perder de vista o interesse da criança. Tal iniciação toma o elementar no sentido de rudimentos, sendo que tais rudimentos não são similares à ideia de elementos, das primeiras partes simples de um saber avançado, de um saber científico.

Ainda, segundo nossa análise, a autora acredita que somente os rudimentos podem se articular com os problemas da vida cotidiana e, assim, o aluno aproveita seu saber para resolver problemas práticos.

Nessa concepção não se trata de iniciar o aluno no percurso da ciência, dando-lhe os elementos de cada saber avançado, isto é, a "escola dos primeiros anos é prática, tem caráter terminal e precisa usar o seu tempo formativo para melhor municiar os alunos que dela saírem com os instrumentos úteis à vida de cada um." (VALENTE, 2016a, p. 43).

Assim, visto que o material analisado privilegia a experiência do aluno, sendo auxiliado por ferramentas de seu cotidiano e seu progresso sendo graduado, passando do fácil para o difícil, do concreto para o abstrato, de particularidades para generalidades, podemos inferir que a autora adotou uma pedagogia que remete a heranças empiristas de saberes rudimentares.

\section{REFERÊNCIAS}

ALBUQUERQUE, I. Metodologia da Matemática. Rio de Janeiro: Editora Conquista, 1951.

BORER, V. L. Les savoirs: un enjeu crucial de l'institutionnalisation des formations à l'enseignement. In: HOFSTETTER, Rita et al. Savoirs en (trans)formation - Au cœur des professions de l'enseignement et de la formation. Bruxelles: Éditions De Boeck Université, 2009. p. 41-58.

CHARTIER, R. O mundo como representação. Tradução Andréa Daher e Zenir Campos Reis. Estudos Avançados, São Paulo, v. 5, n. 11, p. 173-191, jan./abr. 1991. Disponível em: <http://www.scielo.br/pdf/ea/v5n1 1/v5n11al0.pdf>. Acesso em: 22 jul. 2012.

HOFSTETTER, R.; SCHNEUWLY, B.; FREYMOND, M. de. Penetrar na verdade da escola para ter elementos concretos de sua avaliação - A irresistível institucionalização do expert em educação (século XIX e XX). In: HOFSTETTER, 
R.; VALENTE, W. R. (Org.). Saberes em (trans)formação: tema central da formação de professores. São Paulo: Editora Livraria da Física, 2017. p. 55-112.

LOURENÇO FILHO, M. B. Educação e Educação Física. Revista Brasileira de Estudos Pedagógicos, Rio de Janeiro, v. V, n. 15, p. 313-328, 1945. Disponível em:

<http://www.publicacoes.inep.gov.br/portal/subcategoria/161/page/16/ite m_page/10>. Acesso em: 20 ago. 2018.

MONARCHA, C. Brasil arcaico, Escola Nova: Ciência, técnica e utopia nos anos 1920-1930. Campinas, São Paulo: Editora UNESP, 2009.

OLIVEIRA, M. A. A Aritmética escolar e o método intuitivo: um novo saber para o curso primário (1870 - 1920). 280 f. Tese (Doutorado em Ciências) Universidade Federal de São Paulo - UNIFESP, Escola de Filosofia, Letras e Ciências Humanas, Guarulhos, São Paulo, 2017.

PINTO, N. B. Matrizes teóricas dos saberes elementares matemáticos da escola primária em tempos de Primeira República. Revista Diálogo

Educacional, v. 17, n. 51, p. 185-205, jul. 2017.

TROUVÉ, A. La notion de savoir élémentaire à école. Paris: L'Harmattan, 2008.

UFSC - Universidade Federal de Santa Catarina. Repositório Institucional.

Disponível em: <https://repositorio.ufsc.br>. Acesso em: 19 jan. 2018.

VALENTE, W. R. Elementar - cadernos de trabalho. São Paulo: Editora Livraria da Física, 2015a. v. 1.

VALENTE, W. R. História da Educação Matemática nos anos iniciais: a passagem do simples/complexo para o fácil/difícil. Cadernos de História da Educação, v. 14, n. 1, p. 357-367, jan./abr. 2015b. Disponível em: <http://www.seer.ufu.br/index.php/che/article/view/32131>. Acesso em 28 jul. 2016.

VALENTE. W. R. A Matemática nos primeiros anos escolares: elementos ou rudimentos? Revista História da Educação [online]. Porto Alegre, v. 20, n. 49, p. 33-47, maio/ago. 2016 a.

VALENTE. W. R. A era dos testes e a Pedagogia Científica: um tema para pesquisas na Educação Matemática. Revista de Ensino de Ciências e Matemática [online], Canoas, v. 16, n. 1, p.11-26, 2016b. Disponível em: <http://www.periodicos.ulbra.br/index.php/acta/article/view/637>. Acesso: 10 ago. 2018.

VALENTE, W. R. Dos livros didáticos para os cadernos de matemática: a emergência dos saberes profissionais. Zetetiké (online), v. 25, p. 254, 2017a. 
VALENTE, W. R. Os saberes para ensinar Matemática e a profissionalização do educador matemático. Revista Diálogo Educacional, v. 17, n. 51, p. 207-222, jul. 2017b.

VALENTE, W. R. A Matemática a ensinar e a Matemática para ensinar: os saberes para a formação do educador matemático. In: HOFSTETTER, R.;

VALENTE, W. R. (Org.). Saberes em (trans)formação: tema central da formação de professores. São Paulo: Editora Livraria da Física, 2017c. p. 201 228.

VIDAL, D. G. Escola Nova e o processo educativo (1920-1930). In: LOPES, E. T.; FARIA FILHO, L. M.; VEIGA, C. G. (Orgs.). 500 anos de educação no Brasil, 2. ed. Belo Horizonte: Autêntica, 2000. v. 1, p. 497-517.

VILLELA, L.; LACAVA, A. G.; COSTA, D. A.; FRANCA, D. M. A.; SALVADOR, H. H. de F. Os experts dos primeiros anos escolares: a construção de um corpo de especialistas no ensino de Matemática. In: PINTO, N. B.; VALENTE, W. R. (Org.). Saberes elementares matemáticos em circulação no Brasil. São Paulo:

Editora Livraria Física, 2016. v. 1, p. 245-253.

Recebido em: 28 de setembro de 2018.

Aprovado em: 23 de janeiro de 2019. 